\title{
Fracture Initiation, Gas Ejection, and Strain Waves Measured on Specimen Surfaces in Model Rock Blasting
}

\author{
Zong-Xian Zhang ${ }^{1}$ (D) $\cdot \mathrm{Li}_{\text {Yuan }} \mathrm{Chi}^{2} \cdot$ Yang Qiao $^{1} \cdot$ De-Feng Hou ${ }^{1}$
}

Received: 3 June 2020 / Accepted: 30 October 2020 / Published online: 17 November 2020

(c) The Author(s) 2020

\begin{abstract}
Crack velocity, gas ejection, and stress waves play an important role in determining delay time, designing a blast and understanding the mechanism of rock fragmentation by blasting. In this paper, the emerging times of the earliest cracks and gas ejection on the lateral surfaces of cylindrical granite specimens with a diameter of $240 \mathrm{~mm}$ and a length of $300 \mathrm{~mm}$ were determined by high-speed photography, and the strain waves measured by an instrument of dynamic strain measurement during model blasting. The results showed that: (1) the measured velocity of gas penetration into the radial cracks was in a range of 196-279 $\mathrm{m} / \mathrm{s}$; (2) the measured velocity of a radial crack extending from the blasthole to the specimen surface varied from 489 to $652 \mathrm{~m} / \mathrm{s}$; (3) the length of strain waves measured was about $2800 \mu \mathrm{s}$, which is approximately 1000 times greater than the detonation time. At about $2850 \mu$ s after detonation was initiated, gases were still ejected from the surface cracks, and the specimens still stood at their initial places, although surface cracks had opened widely.
\end{abstract}

Keywords Model blasting $\cdot$ Rock fracture $\cdot$ Gas ejection $\cdot$ Stress wave $\cdot$ High-speed camera

\section{Introduction}

High explosives have been widely used in hard rock mining and various kinds of rock engineering for over one century. However, up to now, blast results in hard rock mining and rock excavation have not been satisfactory yet. For example, energy efficiency in rock blasting has been very low (Langefors and Kihlström 1963; Ouchterlony et al. 2004; Sanchidrián et al. 2007), and blast operation has been dominated by empirical design which results in considerable mineral loss, poor safety, high vibrations, explosive wastage, and induced seismic events (Zhang 2016). One reason for the unsatisfactory blast results is that the fragmentation mechanism in rock blasting has not been very clear so far, although detonation theory and blasting science have been developed for several decades (e.g., Johansson and Persson 1970; Langefors and Kihlström 1963; Persson et al. 1994; Cooper 1996; Fickett and Davis 2000; Zhang 2016). In the earliest studies on rock

Zong-Xian Zhang

zongxian.zhang@oulu.fi

1 Oulu Mining School, University of Oulu, 90014 Oulu, Finland

2 State Key Laboratory of Explosion Science and Technology, Beijing Institute of Technology, Beijing 100080, China blasting, there were two viewpoints on the mechanism of rock fragmentation. One viewpoint considered that stress wave played a predominant role in rock fragmentation (e.g., Hino 1954; Duvall and Atchison 1957), and the other indicated that high-pressure gas took the dominant part in rock fragmentation (e.g. Langefors and Kihlström 1963; Clark and Saluja 1964). Since the 1970s, one more viewpoint has been found to be more acceptable on the mechanism of rock fragmentation. This viewpoint states that it is the combined effect of both stress wave and gas pressure that dominate rock fragmentation (e.g., Kutter and Fairhurst 1971; Field and Ladegaard-Pedersen 1971; Bhandari 1979; Dally et al. 1975; Fourney et al. 1993; Fourney 2015).

Another reason for the unsatisfactory blast results is that many basic parameters in rock blasting have not been well determined such as crack propagation velocity, gas penetration speed, and characteristics of stress waves induced in the rock. To understand the mechanism better and improve blast results, various model blasts have been carried out, dealing with stress waves, gas pressure, and fragmentation (e.g., Field and Ladegaard-Pedersen 1971; Bergmann et al. 1973; Fourney et al. 1974, 1981; Dally et al. 1975, 1993, 2006; Katsabanis et al. 2006, 2014; Tilert et al. 2007; Johansson and Ouchterlony 2013; Onederra et al. 2013; Sun 2013; Fourney 2015; Liu et al. 2018; Chi et al. 2019a, b, c; Yang 
et al. 2019; Zhang et al. 2020a, b; Mao et al. 2020; Jeong et al. 2020). In a number of the previous model blasts, a high-speed camera was used to monitor the blasting process (Chi et al. 2019a, b, c; Zhang et al. 2020a, b; Jeong et al. 2020) and the initiation times of the earliest cracks and gas ejection of a few specimens were approximately determined (Chi et al. 2019a, c). In many other experimental studies using rock, concrete, mortar, and rock-like specimens, strain waves were measured either on the free surfaces of models or within the mortar or concrete models during blasting (e.g., Dally et al. 1975; Johansson and Ouchterlony 2013; Sun 2013; Liu et al. 2018; He et al. 2018; Chi et al. 2019a, c; Mao et al. 2020). However, the studies combining the determination of fracture initiation and gas ejection with the strain wave measurement are few. Regarding the above background, this paper presents our experimental results for fracture initiation, gas ejection, and strain waves measured on the specimen surfaces during blasting, and compare the fracture development and gas ejection at different times with the strain waves measured. At last, some topics such as the length of strain waves and relation between the gases and strain waves in blasting are discussed.

\section{Experiments}

\subsection{Rock and Explosive}

Eight rock specimens blasted in this study came from a granite quarry in the suburb of Beijing, China. All specimens were cylinders with a diameter of $240 \mathrm{~mm}$ and a length of $300 \mathrm{~mm}$. The detailed sizes of the specimens are listed in Table 1. One of the rock specimens, S1, is shown in Fig. 1. The density of the granite was $2650 \mathrm{~kg} / \mathrm{m}^{3}$, Poisson's ratio 0.23 , Young's modulus $42.6 \mathrm{GPa}$, average P-wave velocity $4200 \mathrm{~m} / \mathrm{s}$, and dynamic uniaxial compressive strength $120 \mathrm{MPa}$ at a strain rate of $95 \mathrm{~s}^{-1}$. There were no visible joints and other weaknesses on the specimens.
The explosive pentaerythritol tetranitrate (PETN) with a critical diameter of 1-1.5 mm (Kubota 2001; Zhang 2016) was used in this study. The explosive had a density of $0.93 \mathrm{~g} /$ $\mathrm{cm}^{3}$, explosion heat of $5925 \mathrm{~kJ} / \mathrm{kg}$, and a velocity of detonation (VOD) of $5300 \mathrm{~m} / \mathrm{s}$. Explosive charge length was about $15 \mathrm{~mm}$ for all specimens except for S7 whose charge length was $20 \mathrm{~mm}$. Detonator length was about $70 \mathrm{~mm}$. The stemming conditions were different in these eight specimens, as shown in Fig. 1c and Table 1, to investigate the effect of stemming conditions on fracture initiation and gas ejection.

\subsection{Determination of Gas Penetration Velocity and Fracture Initiation Time}

The blasts were performed in an explosion chamber at Beijing Institute of Technology. As shown in Fig. 1, each specimen was placed on a wood board that was on the top of a steel frame placed on the floor of the explosion chamber with a diameter of $8 \mathrm{~m}$. The height of the steel frame was approximately equal to the height of the bullet-proof window of the chamber. Through the window, a high-speed camera standing outside of the chamber could film the blasting process. The steel frame and rock specimen as well as the wood board were enclosed by a steel box with a size of $1 \times 1 \times 2 \mathrm{~m}^{3}$, so that the fragments were mostly kept within the steel box whose front was partly open for photography. To get sharp pictures, the specimen surfaces were cleaned using alcohol before blasting.

The powder PETN explosive was fully loaded at the bottom of the borehole after it was cleaned using alcohol. An electrical detonator was placed on the explosive. Above the detonator, one type of stemming was applied in each borehole, as shown in Fig. 1c. Two materials were used as stemming: steel rod and sand. There was a $1.5 \mathrm{~mm}$ air gap between the steel rod and the borehole wall to host the detonator wires that were taped to the steel rod before blasting. In this case, the stemming using steel rods is actually a partial stemming along the borehole, while the sand stemming

Table 1 Parameters of rock specimens, explosive, stemming, and charge conditions

\begin{tabular}{llllllll}
\hline Specimen no. & $\begin{array}{l}\text { High- } \\
\text { speed } \\
\text { camera }\end{array}$ & $\begin{array}{l}\text { Strain } \\
\text { measure- } \\
\text { ment }\end{array}$ & $\begin{array}{l}\text { PETN }(\mathrm{g}) \\
\text { excluding deto- } \\
\text { nator }\end{array}$ & $\begin{array}{l}\text { Stem length/ } \\
\text { diameter }(\mathrm{mm})\end{array}$ & Stem weight $(\mathrm{g})$ & $\begin{array}{l}\text { Specific } \\
\text { charge }(\mathrm{kg} / \\
\left.\mathrm{m}^{3}\right)\end{array}$ & Stemming \\
\hline S1 & Yes & No & 3.0 & $108 / 14$ & 117 & 0.22 & Partial steel stem without air deck \\
S2 & Yes & Yes & 3.0 & $125 / 14$ & 134 & 0.22 & Partial steel stem without air deck \\
S3 & Yes & No & 3.0 & $88 / 14$ & 88 & 0.22 & Partial steel stem with air deck \\
S4 & Yes & Yes & 3.0 & $84 / 14$ & 85 & 0.22 & Partial steel stem with air deck \\
S5 & Yes & Yes & 3.0 & $89 / 14$ & 96 & 0.22 & Partial steel stem with air deck \\
S6 & Yes & No & 3.0 & $90 / 17$ & 26 & 0.22 & Full sand stem with air deck \\
S7 & Yes & No & 4.0 & $115 / 17$ & 57 & 0.29 & Full sand stem without air deck \\
S9 & Yes & Yes & 3.0 & $116 / 17$ & 67 & 0.22 & Full sand stem without air deck \\
\hline
\end{tabular}




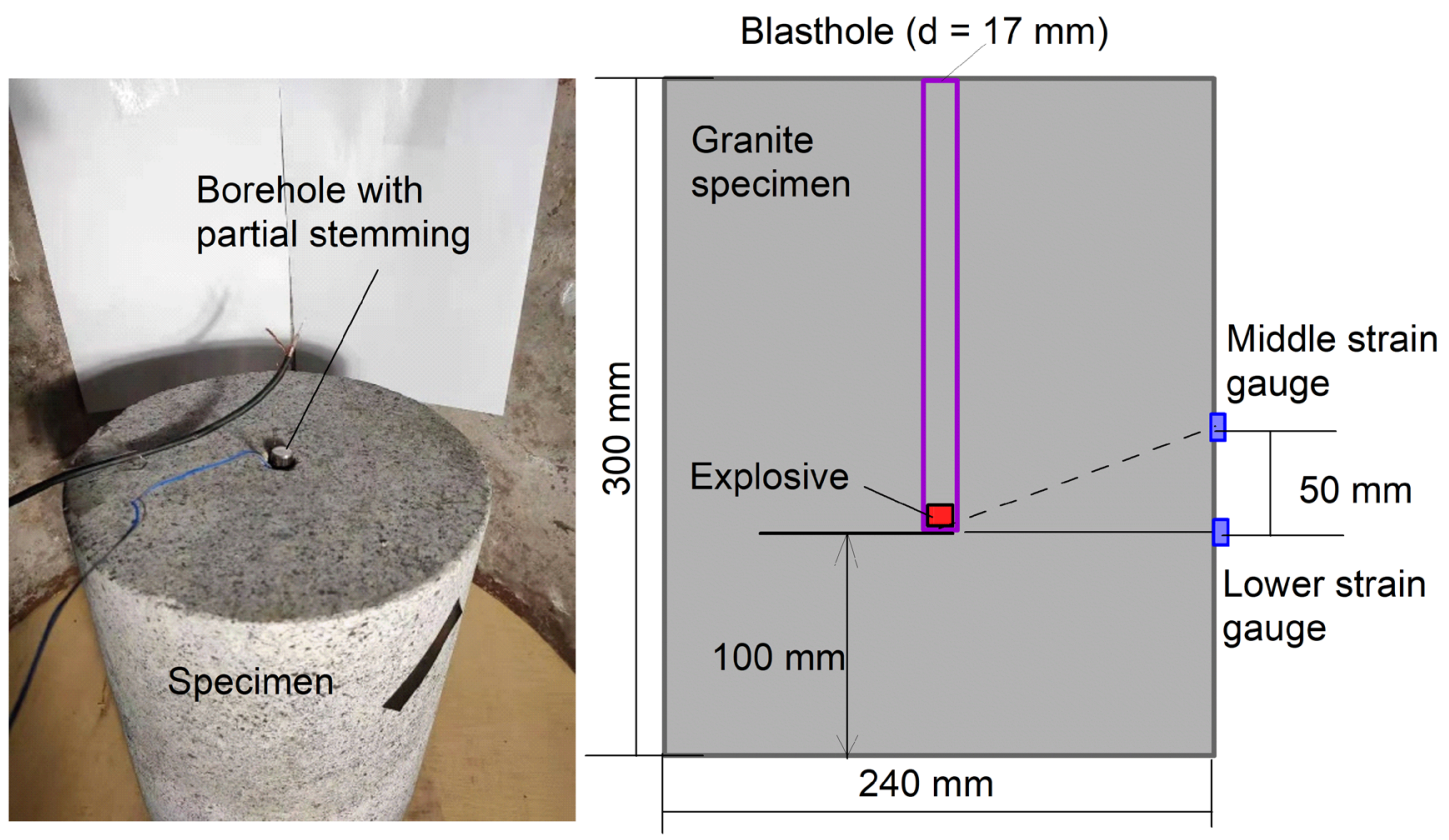

(a)

(b)

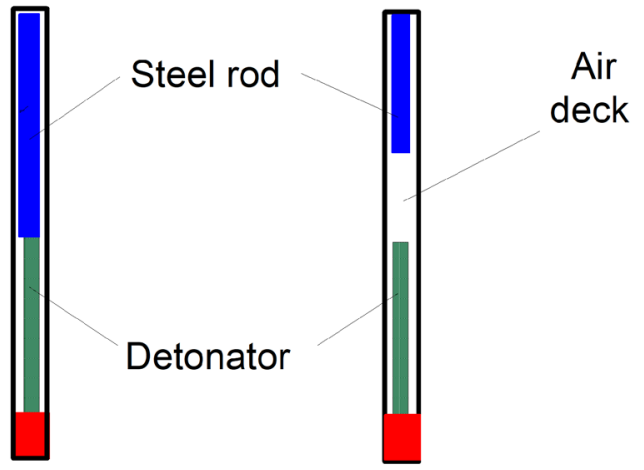

S1 \& S2

\section{S3, S4 \& S5}

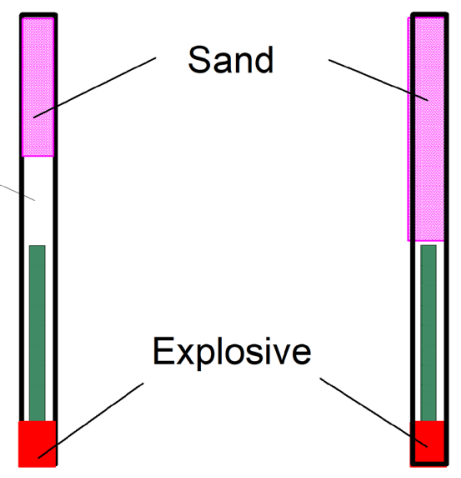

S6
S7 \& S9

\section{(c)}

Fig. 1 Experimental set-up for blasting. a Cylindrical granite specimen S1; b diagram of the cross-section of a specimen where two strain gauges were attached on the surface of specimen; $\mathbf{c}$ stemming condition of each specimen (not in scale)

is full stemming without that gap. In the axial direction of specimens S3-S5, a thin-plastic bag containing only air was placed to separate the detonator and the stemming as an air deck (Fig. 1c). In the stemming of S6, a similar air deck was used. The detailed parameters related to the explosive charge, detonator, and stemming in each specimen are given in Table 1.

To determine the initiation times of gas ejection and crack appearance on the lateral surfaces of specimens, it was necessary to synchronize the initiation of detonation and the triggering of high-speed camera as accurately as possible. To do so, one end of two parallel enameled wires was fixed on the detonator and the other end of the wires connected to the cable from the trigger of the camera. When the detonator was fired, the two wires on the detonator were melt and connected together as a conductor. This signal was sent to the cable from the trigger of the camera, and the camera was triggered. This method has been proved to be 
successful (Chi et al. 2019a, b; Zhang et al. 2020a, b). Since the lengths of the wires plus the cable are about $6 \mathrm{~m}$ in this study and the electromagnetic wave speed in a vacuum is about $3 \times 10^{8} \mathrm{~m} / \mathrm{s}$, the time for the signal propagating from the detonator to the trigger is approximately 0.02 microsecond, which is definitely ignorable. High-speed camera named Photron Fastcam SA5 was used in this study. Two trigger modes, "Center" and "Start", were available in this camera. As the trigger mode "Center" was chosen and the synchronization mentioned above realized, frame 0 (F0) corresponded to the initiation of the detonation in the blasts. In this way, the initiation moments of gas ejection and fracture on the surfaces of the rock specimens could be determined.

To get clear and sharp pictures from the camera, the framing speed must be proper but not very high. Accordingly, a framing speed of 17,500 frames per second was employed. That is to say, the interval time between two adjacent photos was $57 \mu$ s in this study.

\subsection{Strain Wave Measurement}

On the lateral surface of each specimen, two strain gauges named BHF120-2AA with a sensitive grid size of $2 \times 2 \mathrm{~mm}^{2}$ were attached to measure the tangential stresses during blasting. The two gauges were at $100 \mathrm{~mm}$ and $150 \mathrm{~mm}$ locations from the lower end of the specimen, respectively, as shown in Fig. 1. The two gauges were connected by cables to an instrument, named DH5960, for strain measurement placed outside of the explosion chamber. The strain instrument, the high-speed camera, and the detonator were connected together by one synchronizer to synchronize these three components.

\section{Results and Analysis}

\subsection{Gas Ejection}

In model blasting, gases are often ejected from both the collar of blasthole and some cracks on the surface of rock specimen. If the blasthole is not fully stemmed or sealed, as shown in Fig. 2 for specimen S2, the shock wave from detonation can directly go through the air gap between the steel rod and the wall of blasthole and go out of the hole. Therefore, the light areas in frame $1(\mathrm{~F} 1)$ and frame $2(\mathrm{~F} 2)$ in Fig. 2 are probably the regions occupied by the shock waves, i.e., these light areas are not gases. However, the dark areas outside of the rock specimen should be gases.

By means of the high-speed photographs, the emerging time of gases from the cracks on the surface of a specimen can be determined. Take $\mathrm{S} 2$ as an example, it can be found that in frame 10, gases appear in a vertical crack, but in frames $0-9$, there is no any gas from any crack. Therefore, it can be determined that gases emerged on the surface latest at $570(10 \times 57) \mu$ s after detonation was initiated. In frame 11, gases expand gradually to a larger area. The determined times of the earliest gas ejection from specimen surfaces are summarized for all eight specimens in Table 2. Notice that the determined emerging times of the earliest gases on the surfaces of specimens are greater than the actual emerging times of the earliest gases by a time smaller than $57 \mu$ s which is the interval time between two adjacent photographs in this study.

Considering the limited length of the paper, we only present the high-speed photographs from four specimens S2, S4, S5, and S9 all of which deal with strain measurement during blasting. Figures 2, 3, 4, 5 show all photographs of each specimen starting at frame 0 (the initiation of detonation) and ending at or before frame 11 $(11 \times 57=627 \mu$ s after detonation $)$. According to these photographs, the earliest gas ejection occurred on the surfaces at 399-570 $\mu$ s after the initiation of detonation.

Considering that (1) the radial cracks are often roughly straight (e.g., Chi et al. 2019a, b; Zhang et al. 2020a, b) and (2) the detonation product gases can start to penetrate into the earliest radial cracks from the blasthole as soon as detonation occurs, we can find that the velocity of gas penetration into and travel via the radial cracks is in a range of $196-279 \mathrm{~m} / \mathrm{s}$, corresponding to the gas ejection time $399-570 \mu$ s on the surfaces.

In brief, the measurement results concerning gas ejection can be summarized in the following. (1) The earliest gas ejection occurred on the specimen surfaces at 399-570 $\mu$ s after the initiation of detonation. Correspondingly, the velocity of gas penetration into the radial cracks was in a range of 196-279 m/s. (2) The velocity of gas penetration into the radial cracks is $231 \mathrm{~m} / \mathrm{s}$ on average in three partially stemmed specimens and $245 \mathrm{~m} / \mathrm{s}$ in the fully stemmed specimen, implying that the stemming condition has a certain effect on the velocity of gas penetration into the radial cracks.

\subsection{Earliest Crack Appearing on the Lateral Surfaces of Rock Specimens}

\subsubsection{Emerging Time of Earliest Crack}

Similar to the procedure in determining gas ejection time described above, the time when the first crack appeared on the surface of a specimen can be determined according to the photographs from the high-speed camera. The results are shown in Table 2. Obviously, the earliest crack appeared at $171 \mu \mathrm{s}$ in five specimens and at $228 \mu \mathrm{s}$ in three specimens after initiation of detonation, respectively. 

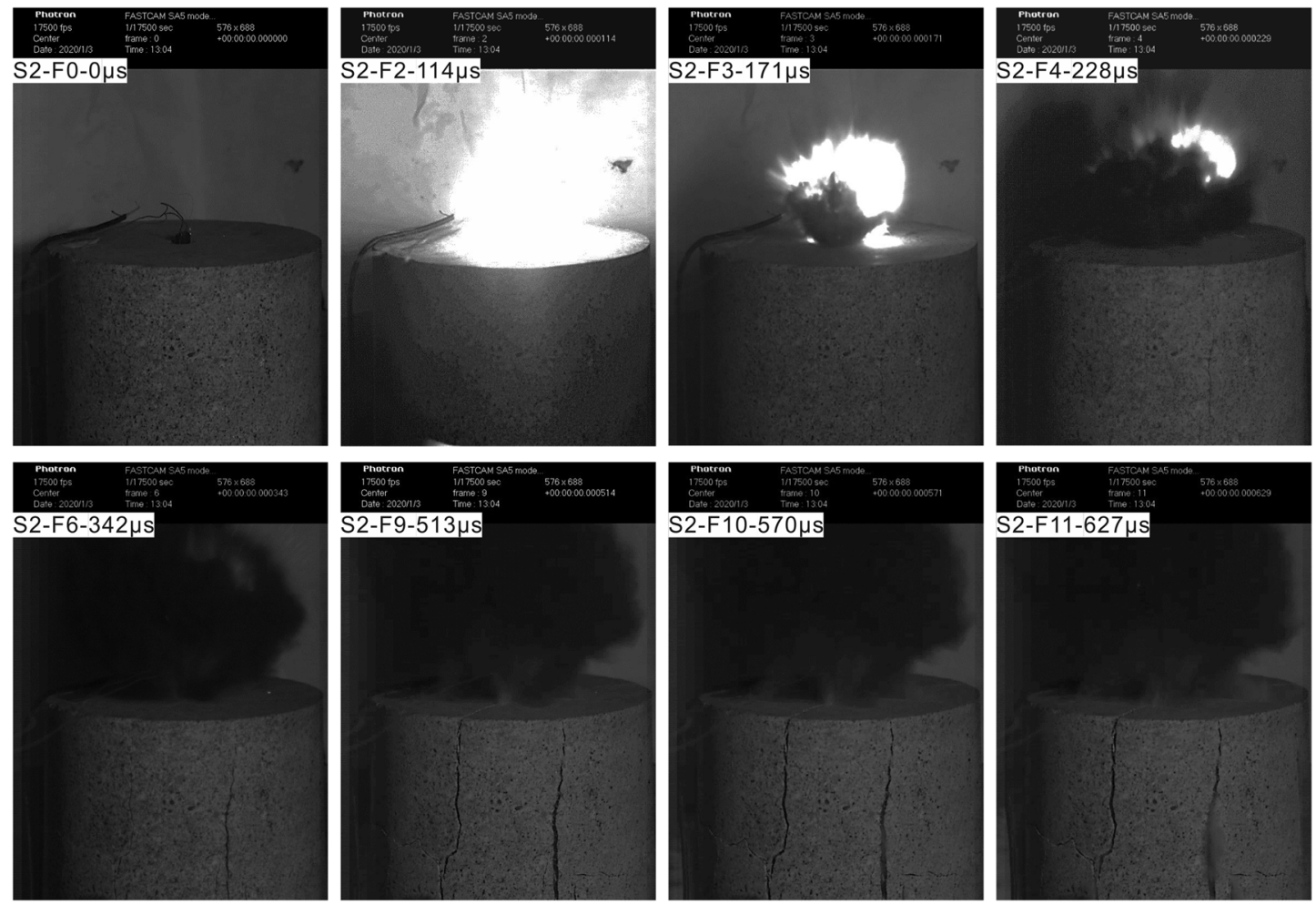

(a)

$\mathrm{S} 2-\mathrm{F} 0-0 \mu \mathrm{s}$
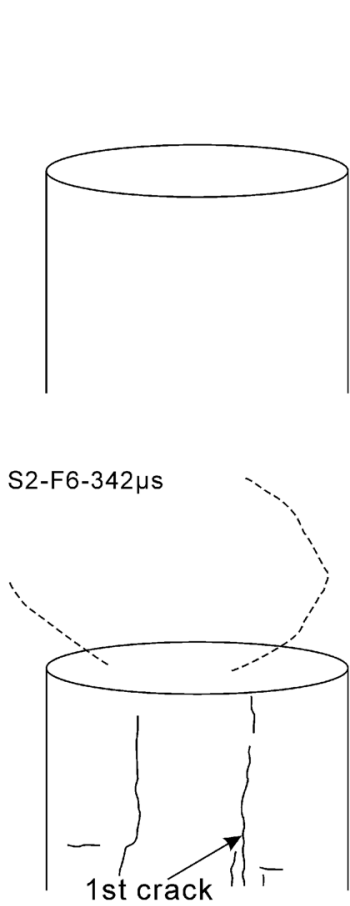

$\mathrm{S} 2-\mathrm{F} 2-114 \mu \mathrm{s}$
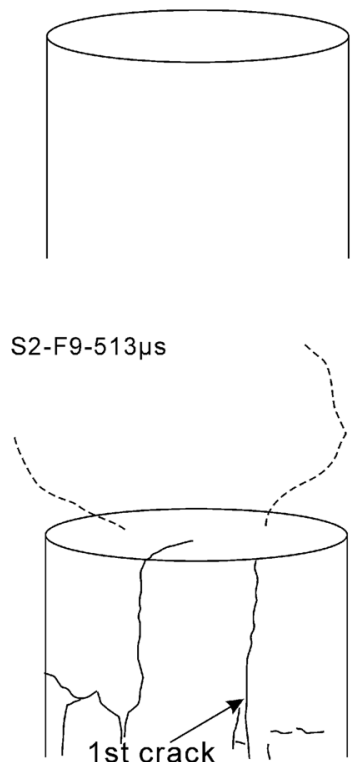

(b)
S2-F3-171 us
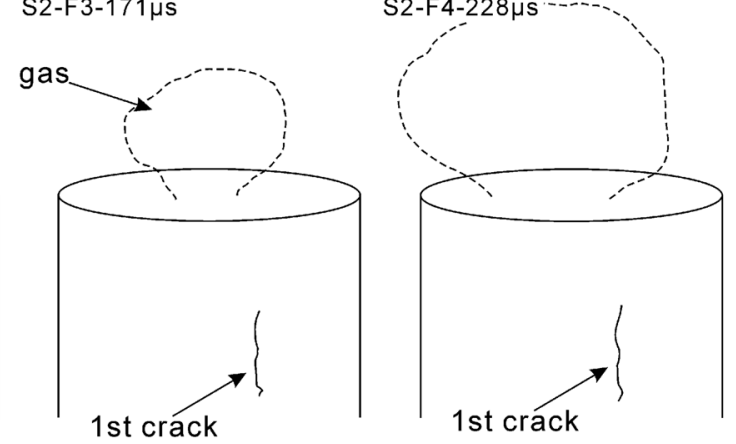

S2-F10-570us
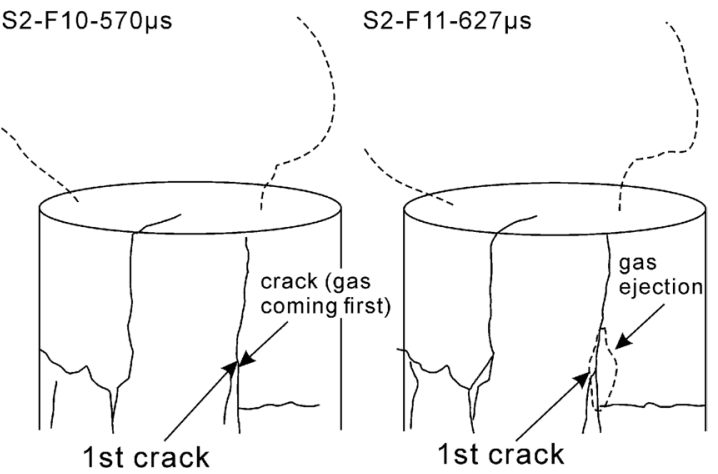

1st crack
S2-F $11-627 \mu \mathrm{S}$

1st crack

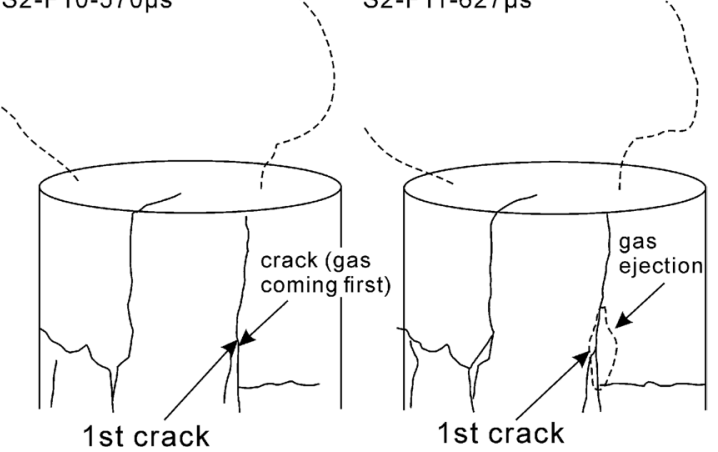

Fig. 2 Photographs (a) and drawings (b) of S2 with partial steel stemming without air deck. F0 (frame 0) was at initiation point of detonation. In F3 (frame 3), one long vertical crack emerged on the right side. In F10 (frame 10) gas escaped from that vertical crack 
Table 2 Earliest crack and gas emerging times on specimen surfaces and gas velocities from collars and surface cracks

\begin{tabular}{lllllll}
\hline Specimen no. & $\begin{array}{l}\text { Time of earliest } \\
\text { crack on surface } \\
(\mu \mathrm{s})\end{array}$ & $\begin{array}{l}\text { Time of earliest } \\
\text { gas on surface } \\
(\mu \mathrm{s})\end{array}$ & $\begin{array}{l}\text { Gas from } \\
\text { earliest } \\
\text { crack }\end{array}$ & $\begin{array}{l}\text { Velocity of } \\
\text { radial crack } \\
(\mathrm{m} / \mathrm{s})\end{array}$ & $\begin{array}{l}\text { Velocity of gas } \\
\text { penetration into crack } \\
(\mathrm{m} / \mathrm{s})\end{array}$ & Stemming \\
\hline S1 & 171 & 513 & Yes & 652 & 217 & $\begin{array}{l}\text { Partial steel stem without air deck } \\
\text { S2 }\end{array}$ \\
S3 & 171 & 570 & Yes & 652 & 196 & Partial steel stem without air deck \\
S4 $^{\text {a }}$ & 171 & 399 & Yes & 652 & 279 & Partial steel stem with air deck \\
S5 $^{\text {a }}$ & 228 & 456 & Yes & 489 & 245 & Partial steel stem with air deck \\
S6 & 171 & 513 & No & - & - & Partial steel stem with air deck \\
S7 & 171 & 513 & No & - & - & Full sand stem with air deck \\
S9 & 228 & 456 & Yes & 489 & 245 & Full sand stem without air deck \\
\hline
\end{tabular}

${ }^{\mathrm{a}}$ With strain measurement

\subsubsection{Velocity of Radial Crack}

As mentioned previously, the radial cracks from blastholes are often straight. Thus, we can determine the extension velocity of the earliest radial crack using the measured fracture initiation time 171-228 $\mu$ s and the distance $111.5 \mathrm{~mm}$ from borehole wall to specimen surface. The results are shown in Table 2, indicating that the velocity of a radial crack extending from the blasthole to the specimen surface varies from 489 to $652 \mathrm{~m} / \mathrm{s}$. Considering a $57 \mu \mathrm{s}$ time interval between two adjacent photographs, the maximum velocity of a radial crack may be up to $652-978 \mathrm{~m} / \mathrm{s}$. According to measurement results from many rocks and rock-like materials summarized in Zhang (2016), crack velocity is directly proportional to the P-wave velocity of the material with a coefficient of $0.1-0.33$. For granite measured by Bergmann et al. (1973), this coefficient is 0.33. Using this value and the parameters of the granite in this study, we can get that the maximum crack velocity of the granite is $0.33 \times 4200=1368 \mathrm{~m} / \mathrm{s}$. Obviously, this maximum crack velocity is greater than either $489-652 \mathrm{~m} / \mathrm{s}$ (the velocities of the radial cracks measured) or $652-978 \mathrm{~m} / \mathrm{s}$ (the possible maximum velocities of radial cracks estimated due to the $57 \mu$ s time interval between two photographs). Since the time from the initiation of detonation to the initiation of the radial crack is considered to be zero (actually not zero) in this study, the actual crack velocity should be greater than $652 \mathrm{~m} / \mathrm{s}$ measured or even greater than $978 \mathrm{~m} / \mathrm{s}$ estimated.

\subsubsection{Difference between Crack Velocity and Gas Velocity}

Compared with the velocity of gas penetration into radial cracks, varying from 196 to $279 \mathrm{~m} / \mathrm{s}$, with the propagation velocity of an earliest radial crack in a range of 489$652 \mathrm{~m} / \mathrm{s}$, the crack velocity is about $1.8-3.3$ times greater than the gas travel velocity.
In summary, the experimental results relevant to crack velocities are as follows. (1) The earliest crack appeared at 171-228 $\mu$ s after the initiation of detonation. Considering the $57 \mu$ interval time between two adjacent high-speed pictures, the possibly earliest crack might appear on the specimen surfaces at $114 \mu$ s after the initiation of detonation. (2) The velocity of a radial crack extending from the blasthole to the specimen surface varies from 489 to $652 \mathrm{~m} / \mathrm{s}$. Considering the $57 \mu$ interval time, the possible maximum velocity of a radial crack may be up to $652-978 \mathrm{~m} / \mathrm{s}$. (3) The velocity of radial crack is about 1.8-3.3 times higher than the velocity of gas penetration into radial cracks.

\subsection{Strain Waves Measured on the Lateral Surfaces of Rock Specimens}

\subsubsection{Length of Strain Wave}

Strain measurement during blasting was carried out in four specimens $\mathrm{S} 2, \mathrm{~S} 4, \mathrm{~S} 5$, and $\mathrm{S} 9$. The measurement results are shown in Figs. 6, 7, 8, and 9. Among eight strain gauges, two lower gauges and one middle gauge failed, showing a constant strain value of $110,000 \mu \varepsilon$ after detonation started.

As soon as the detonator and explosive in each hole were fired, the detonation-caused shock wave started to travel from the blasthole to the free surface of the specimen, taking a time:

$T_{0}=\frac{111.5 \mathrm{~mm}}{4200 \mathrm{~m} / \mathrm{s}}=27 \mu s$.

Accordingly, after $27 \mu$ s when the detonator was initiated, the stress wave, a P-wave, arrived at the strain gauges (first to the lower gauge and then to the middle one) on the surface. In other words, the detonation started $27 \mu$ s earlier than the initiation point of the strain waves measured. Thus, the point noted with F0 (frame 0) in Figs. 6, 7, 8, and 9 means the detonation initiation time, and the corresponding 

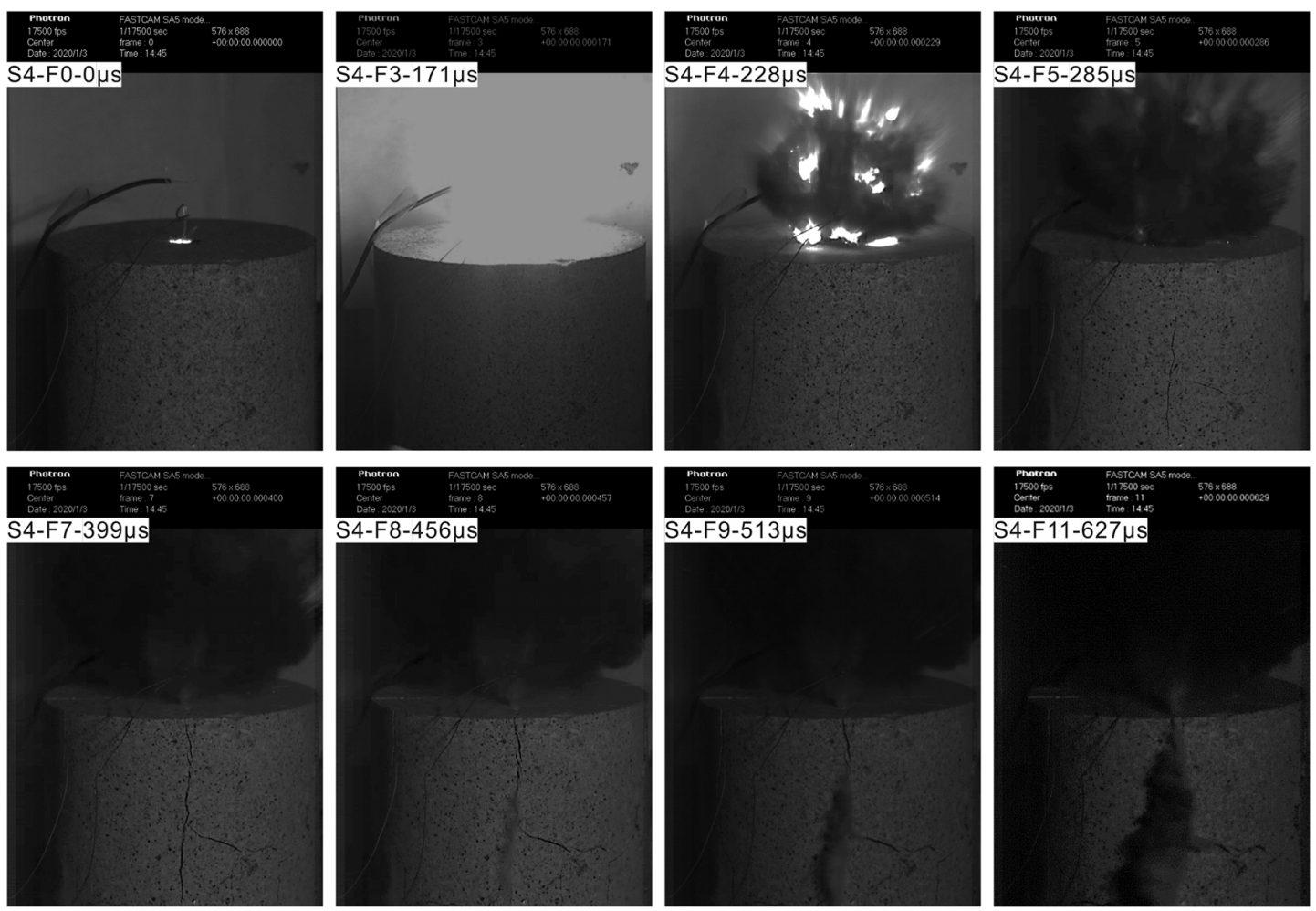

(a)

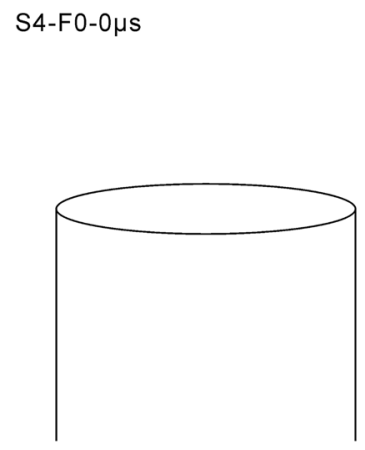

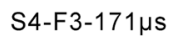

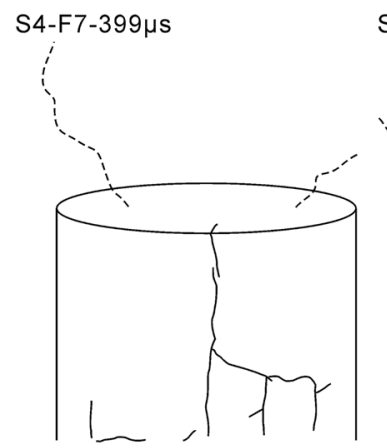

S4-F8-456 Hs
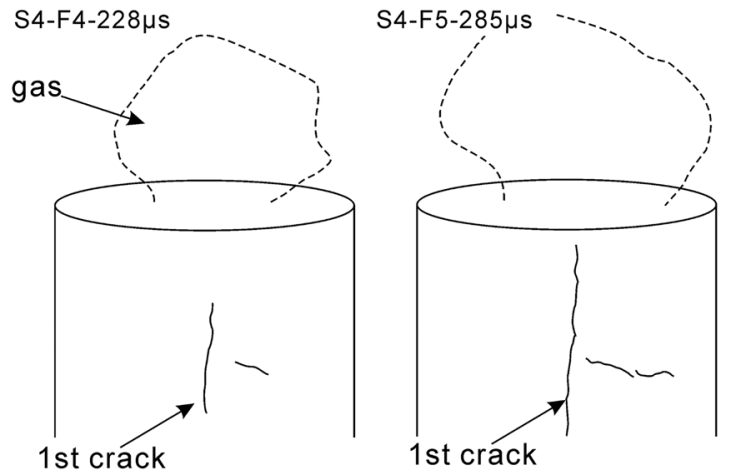

S4-F9-513us

S4-F11-627us
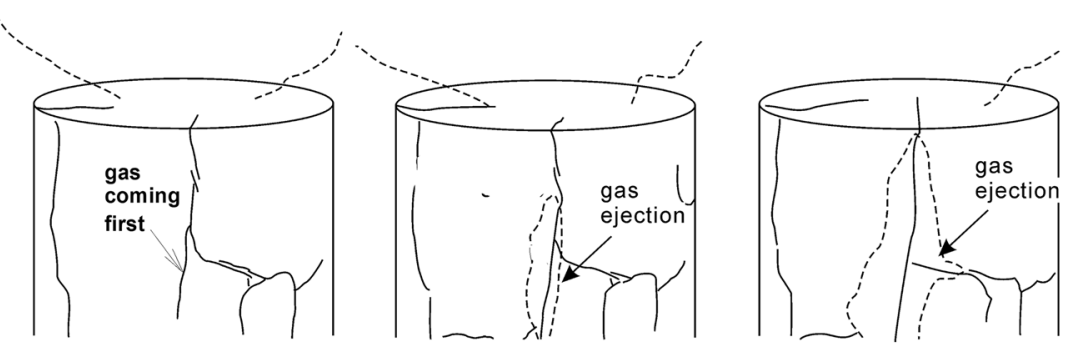

(b)

Fig. 3 Photographs (a) and drawings (b) of S4 with partial steel stemming with air deck. F0 (frame 0) was at initiation point of detonation. In F4 (frame 4), one long vertical crack emerged in the center of the front surface. In F8 (frame 8), gas escaped from that vertical crack 

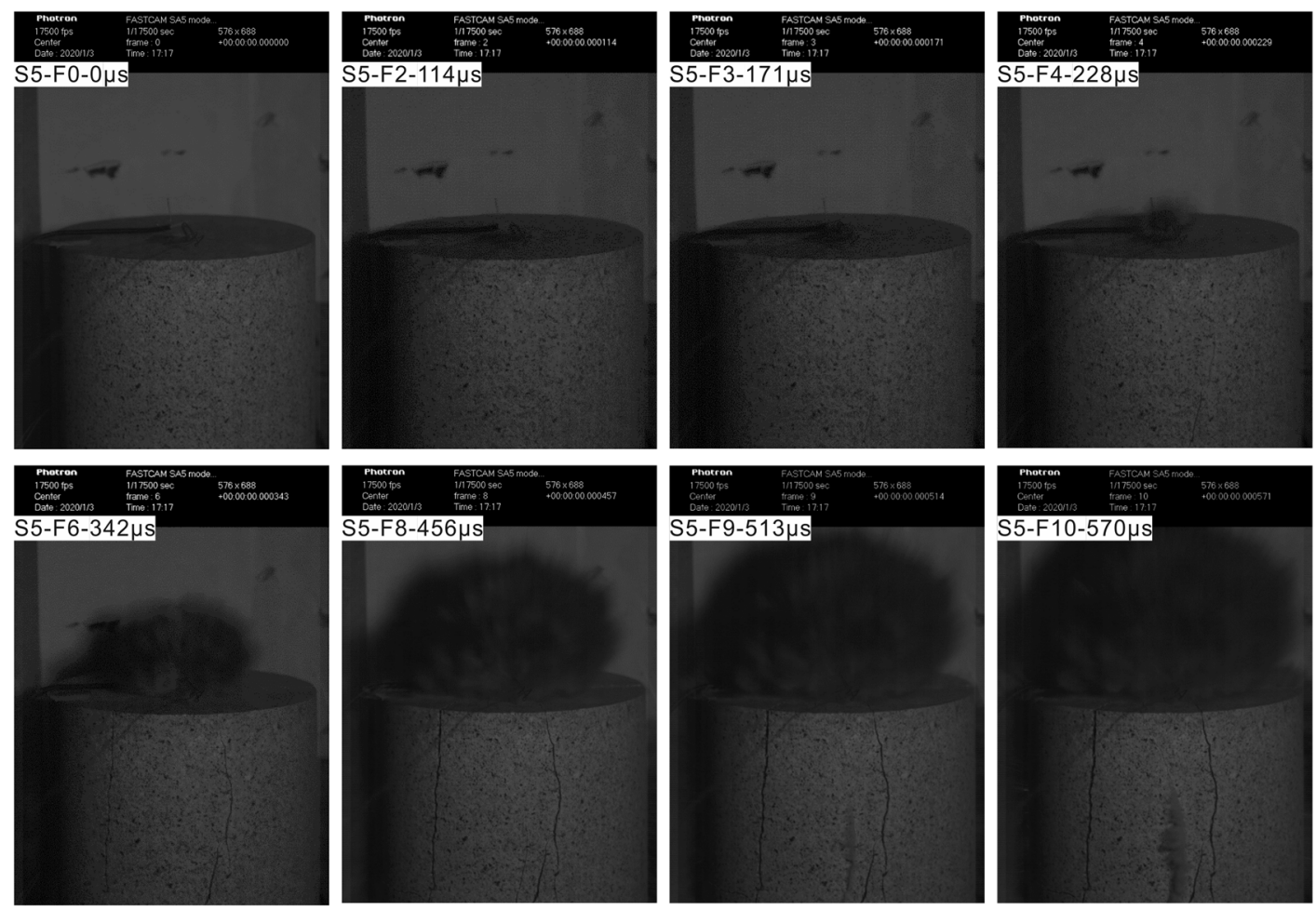

(a)

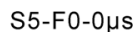

S5-F2-114us

S5-F3-171us

S5-F4-228us
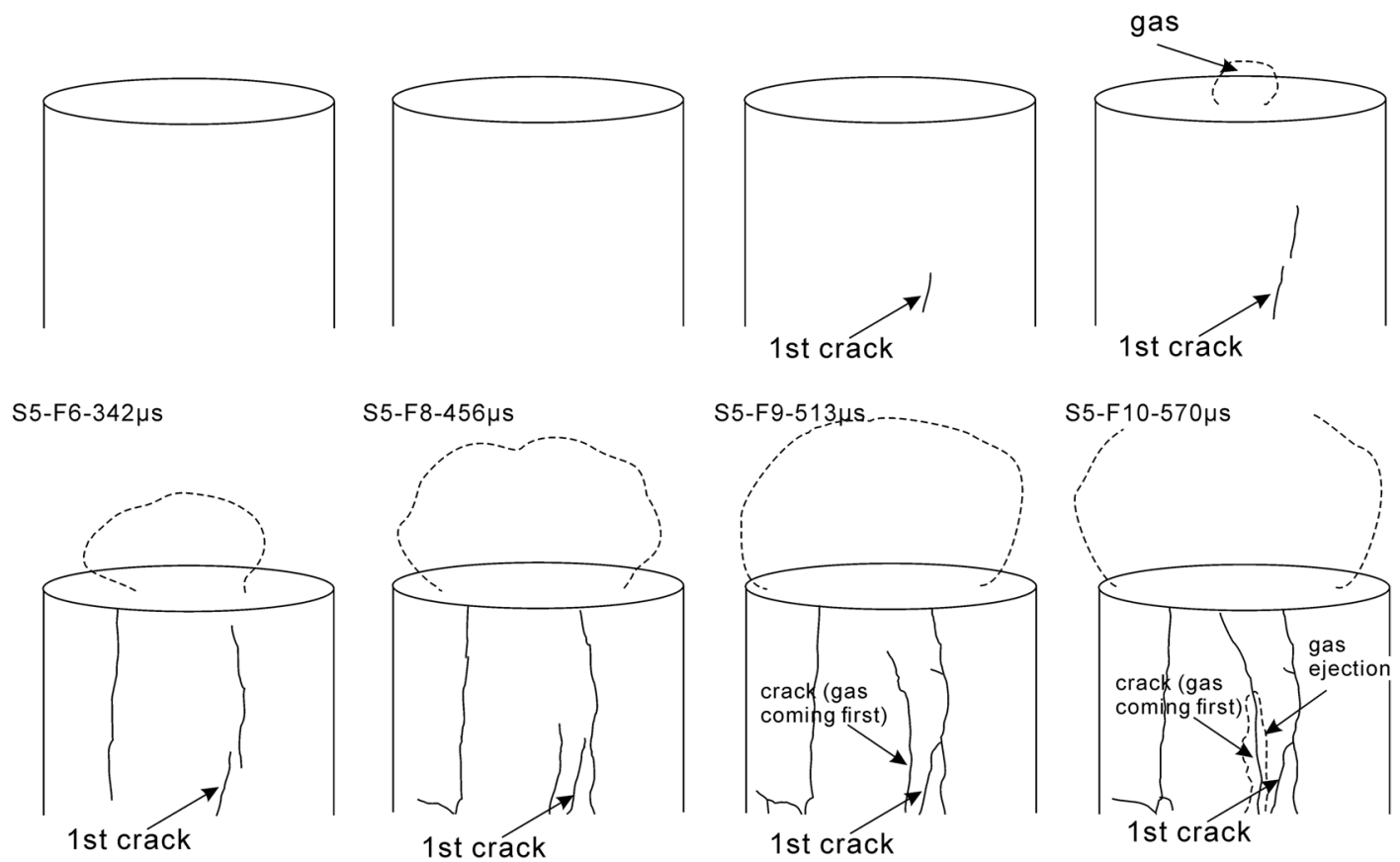

(b) 
४Fig. 4 Photographs (a) and drawings (b) of S5 with partial steel stemming and air deck. F0 (frame 0) was at initiation point of detonation. In F3 (frame 3), one nearly vertical crack emerged on the right side close to the middle of the front surface. In F9 (frame 9), gas escaped from one small vertical crack that can be seen the first time in F7 (frame 7). This small crack must have started from the borehole. Note that there is no gas coming out of the earliest crack until frame 29 $(29 \times 57$ microseconds), indicating that this earliest crack might start from the surface of the specimen rather than the blasthole

photographs with frame 0 are presented in Figs. 2, 3, 4, and 5. Similarly, the points noted with F20, F30, F40, and F50 in Figs. 6, 7, 8, and 9 correspond the times $1140(20 \times 57)$ $\mu \mathrm{s}, 1710(30 \times 57) \mu \mathrm{s}, 2280(40 \times 57) \mu \mathrm{s}$, and $2850(50 \times 57)$ $\mu$ after the initiation of detonation. The photographs taken at these times are shown in Figs. 6, 7, 8, and 9.

Figures 6, 7, 8, 9 show that the lengths (duration) of the strain waves are roughly $2850-27=2823 \mu$ from the middle strain gauges in S2, S4, and S5. In other words, the strain waves end around F50 (2850 $\mu \mathrm{s})$, and after $2850 \mu \mathrm{s}$, the strains are very small and they can be neglected. The lengths of the strain waves are difficult to determine from the lower gauges in S5 and S9, since the strains at the time $4800 \mu \mathrm{s}$ are still high, e.g., the strain is about $800 \mu \varepsilon$ and $1600 \mu \varepsilon$ at time $4800 \mu$ s in S5 and S9, respectively. Since the velocity of detonation was $5300 \mathrm{~m} / \mathrm{s}$ and the explosive charge length was $15 \mathrm{~mm}$ in these four specimens, the total detonation time of the explosive charge in specimen would be equal to $2.8 \mu \mathrm{s}$, meaning that the lengths of the strain waves measured from the middle gauges are about 1000 times greater than the length of the detonation time.

\subsubsection{Gas Ejection and Rock Fracture Process}

According to Figs. 6, 7, 8, and 9, until $2850 \mu$ s (F50) after detonation, gases had been escaping from some surface cracks, but the specimens had not been completely disassembled apart yet. At the same time, those surface cracks were opening further and gas ejection from them was occurring continuously. Furthermore, all peak strains of four specimens appeared before $1140 \mu \mathrm{s}$ (F20) after detonation. From 1140 to $2850 \mu$ s, gas ejection was still going on and each specimen was still standing at its original place even though it had been fractured, indicating that the detonation product gases were still acting on the fractured specimen with a certain pressure, as shown in Figs. 6, 7, 8, and 9.

\subsubsection{Shape of Strain Waves}

As shown in Figs. 6, 7, and 8, the waveforms from the middle gauges in S2, S4, and S5 are different from one another. Similarly, the waveforms from the lower gauges in S5 and S9 are different from each other, as shown in Figs. 8 and 9. In addition, the amplitudes of all the waves have large difference.
One reason is that the waveform and amplitude of a strain wave measured are affected by the locations of both cracks nearby and the gauge in question. In other words, the strain wave shape and its amplitude measured by the gauge are influenced by the wave interaction with the cracks surrounding the gauge and by the wave reflection from the boundaries of the specimen.

\subsubsection{Effect of Gauge Location on Strain Waves}

Figures $6,7,8,9$ show that the lengths of the strain waves from the lower gauges on S5 and S9 are much longer than the lengths from the middle gauges on $\mathrm{S} 2$, S4, and S5. In addition, the shapes of the strain waves from the middle gauges are different from the lower gauges, too. This indicates that the location of strain gauge has impact on the length and shape of a measured strain wave. One of the reasons for these differences is that a lower gauge in a specimen is closer to both the explosive and the lower end of the specimen (see Fig. 1b), resulting in both the detonation-induced stress wave and the reflected wave from the lower end of the specimen arrive earlier to the lower gauge than to the middle gauge.

In brief, the results related to the length of strain wave can be summarized in the following. (1) The length of strain wave measured was around $2823 \mu \mathrm{s}$, which is about 1000 times greater than the detonation time. (2) Gas ejection from some surface cracks occurred at least to $2850 \mu$ s (F50) after detonation, and at that moment, the specimens were not completely disassembled apart yet. (3) All peak strains of four specimens appeared before $1140 \mu$ s (F20) after detonation. (4) The shapes and amplitudes of the strain waves measured by different gauges at different locations and in different specimens did not have clear similarity.

\subsection{Effect of Stemming Conditions}

According to the high-speed photographs in Figs. 2, 3, 4, and 5 , gas ejection from the collar is much earlier from the partially stemmed specimens than that from the fully stemmed specimen. For example, the earliest gas ejection can be seen at $228 \mu$ s from the collars of the partially stemmed S2, S4, and S5, but at $399 \mu$ s from the collar of the fully stemmed S9. This indicates that a fully stemmed borehole makes more gas energy kept in the rock, but a partially stemmed borehole results in more gas energy loss from its collar.

\section{Discussion}

\subsection{Crack Extension and Gas Penetration Velocities}

As soon as a crack is formed or a crack starts to propagate in the rock during blasting, the stress or strain field 

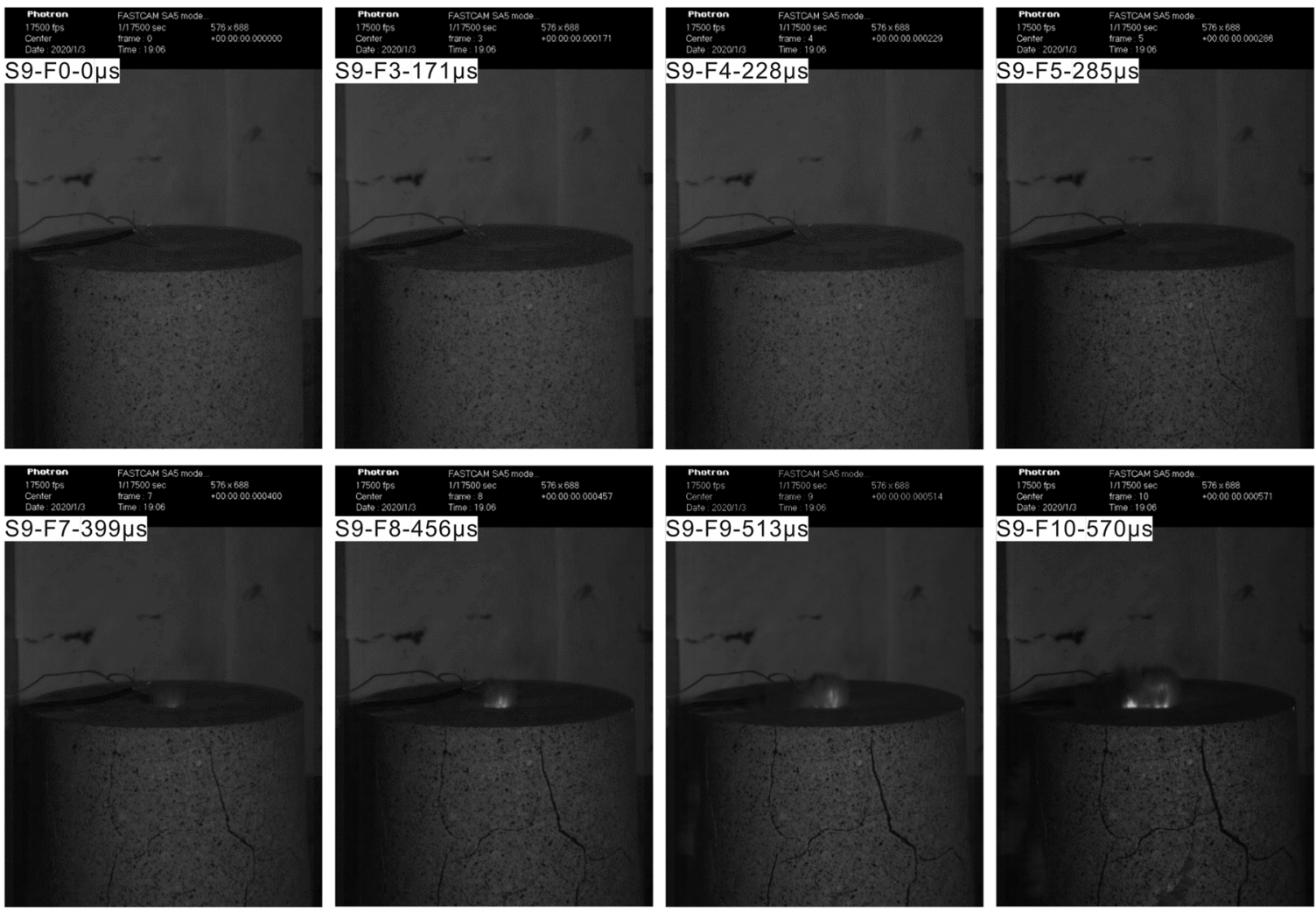

(a)
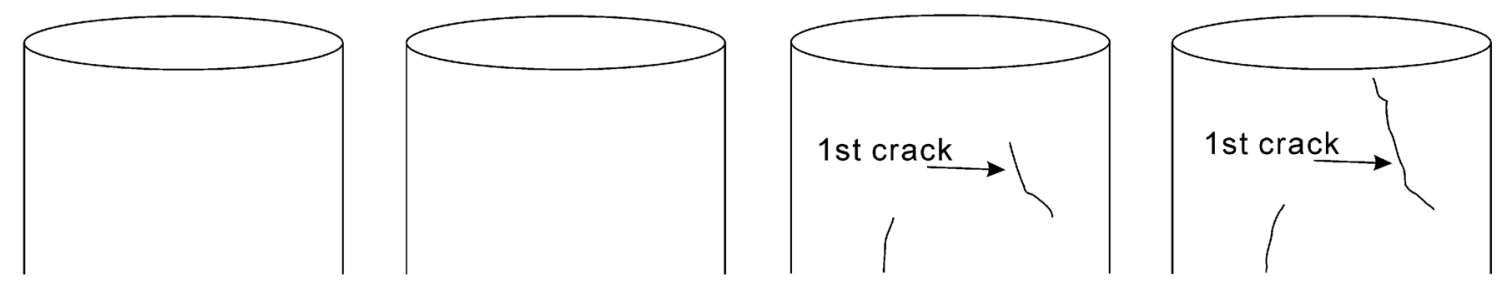

S9-F7-399us

S9-F8-456us

S9-F9-513us

S9-F10-570us
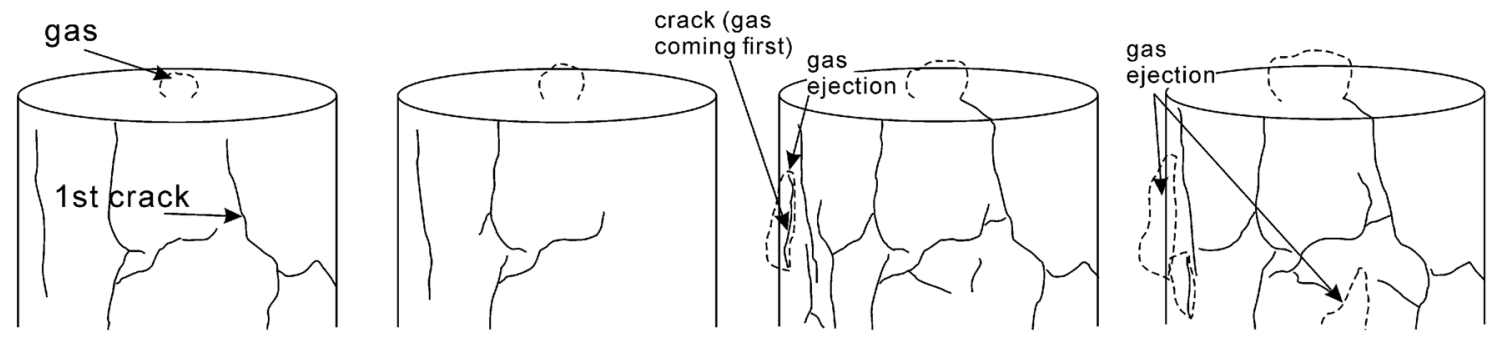

(b) 
४Fig. 5 Photographs (a) and drawings (b) of S9 with full sand stemming without air deck. F0 (frame 0) was at initiation point of detonation. In F4 (frame 4), two slightly inclined cracks emerged in the left (from lower of the picture) and right side (from upper picture), respectively. In F9 (frame 9), earliest gas ejection appeared from one small crack on the left side of specimen. Note that there was no gas ejection from the earliest two cracks until frame $11(11 \times 57 \mu \mathrm{s})$, meaning that the earliest cracks might start from the surface but not the blasthole

is immediately changed in the surrounding rock. Accordingly, to determine a correct delay time in multihole blasting, crack propagation velocity in blasting is a necessary factor, in addition to other ones such as stress distribution, detonation waves, confinement and boundary conditions, vibrations in the far field, movement of fragments, etc. (Zhang 2016). Similarly, gas penetration velocity is a necessary factor in making a blast design. For example, this velocity can be used to estimate the time when gas ejection begins in the free surface or bench face, or check whether the stemming is or not sufficient. Bearing in mind that the chemical reaction time is neglected and the initiation of the detonator is assumed to be at the same moment as the explosive is fired in this study. In fact, these times are certainly not zero. As a result, the determined crack velocity $652 \mathrm{~m} / \mathrm{s}$ using the high-speed photography must be smaller than the actual crack velocity. Similarly, the possible maximum crack velocity might be greater than $978 \mathrm{~m} / \mathrm{s}$ due to the $57 \mu$ s interval time between two adjacent photographs. To determine the crack velocity more accurately, a higher framing speed than 17,500 frames per second need to be tried, but the distance between the camera and the rock specimen should be decreased. In addition, notice that the measured crack velocities are much different from each other, i.e., the crack velocities vary in a notable range of 489-652 m/s. Similarly, the measured gas velocities vary in a marked range of $196-279 \mathrm{~m} / \mathrm{s}$. These notable differences may result from several reasons. Two such reasons are in the following. (1) Only one high-speed camera was used in this study and the camera was only able to film the front side (about half) of the specimen, while the backside could not be filmed. In this case, when the earliest crack appeared on the front side of the specimen, it could be certainly filmed. However, when the earliest crack occurred on the backside, the camera could not record it. Instead, the camera was only able to record "the earliest crack"(which appeared after the earliest crack on the backside) on the front side. (2) The radial cracks caused by blasting are randomly distributed, resulting in an uncertain position for the earliest crack. Therefore, it is better to have two high-speed cameras (one films the front side, while the other does the backside) in the future model blasting.

\subsection{Length of Strain Waves}

The length of the strain waves measured from the middle strain gauges in this study is about $2823 \mu$ s, which is very long, compared with detonation time, as mentioned earlier. Such long wavelength is much greater than that reported by other investigators. For example, Johansson and Ouchterlony (2013) measured a wavelength of less than $400 \mu$ s in smallscale bench blasting, and Liu et al. (2018) presented a wavelength of approximately $30 \mu$ s in a confined mortar model blasting. Sun (2013) showed that the measured waves were longer than $400 \mu$ s, but he did not present complete wave, i.e., the waves did not have ends. Interestingly, we found that the length of the strain wave of a cubic granite specimen S6 in Chi et al. (2019a) was approximately $1500 \mu$ s, which is much greater than the length measured by other researchers mentioned above. Notice that only the first part (about $200 \mu$ s long) of the strain wave was shown in Fig. 8 in Chi et al. (2019a). The great wavelength in both this study and Chi et al. (2019a) can be explained in the following. The strain wave measured from each strain gauge includes not only the $\mathrm{P}$-wave from detonation but also the $\mathrm{S}$-wave due to breakage of the blasthole. Since the two waves travel with different velocities, the total length of the two waves together increases with increasing travel time or distance. Therefore, if the blasthole is not broken or destroyed, the S-wave will not appear, particularly in cylindrical specimens. In this study, all rock specimens were shattered into numerous fragments including very fine particles, so the S-wave would be strong, resulting in great wavelength. In addition, there are possibly other factors contributing to the great wavelength in this study, but this needs further investigation.

\subsection{Possibility of Crack Initiation from Free Surface}

As shown in Table 2, in five specimens, the earliest gas emerged from the earliest cracks on the surfaces. It can be inferred that these earliest cracks must be radial cracks and they were initiated at or near the blasthole. Finally, these radial cracks propagated to the surfaces of specimens. Via these radial cracks, detonation gases could escape out. On the contrary, in three other specimens, the earliest gas did not emerge from the earliest cracks on the surfaces. Instead, the earliest gas came from a small crack (e.g., see Fig. 4 for S5) that appeared in the surface of specimen much later than the earliest crack in the surface. Based on this fact, it can be inferred that some of the earliest cracks on the surface of a specimen were initiated from the surface rather than the place at or near blasthole. This inference is supported by high-speed photography. As shown in Fig. 4, the earliest gas appeared in a small vertical crack at the middle of front specimen surface. This small crack can be seen the first time in frame 7, while one earliest crack in the left side of the 
Fig. 6 Photographs at $1140 \mu \mathrm{s}$ (Frame 20), $1710 \mu$ s (Frame 30), $2280 \mu$ s (Frame 40), and $2850 \mu$ s (Frame 50) after initiation of detonation of S2 (a) and tangential strain waves measured at middle gauge (b) and lower gauges (c) on the specimen
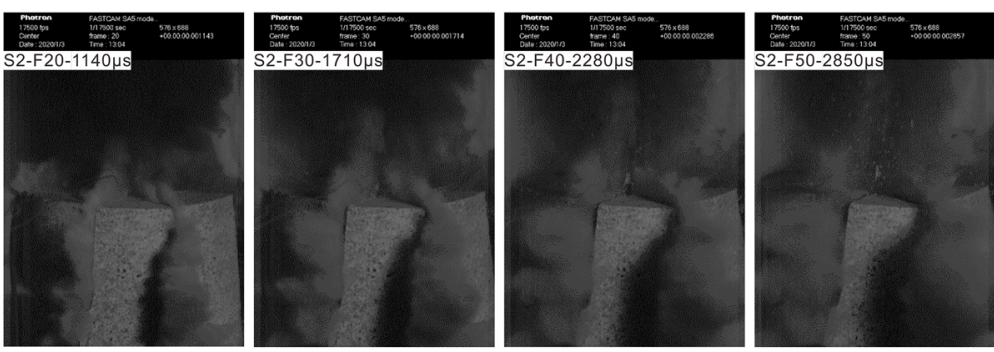

(a)

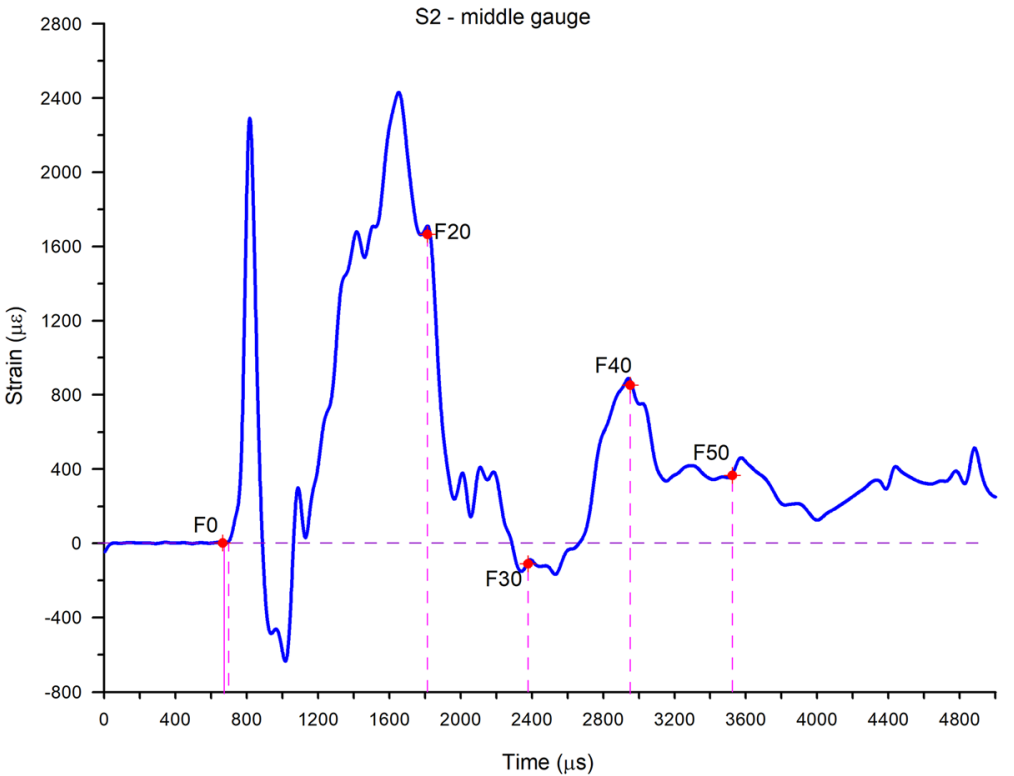

(b)

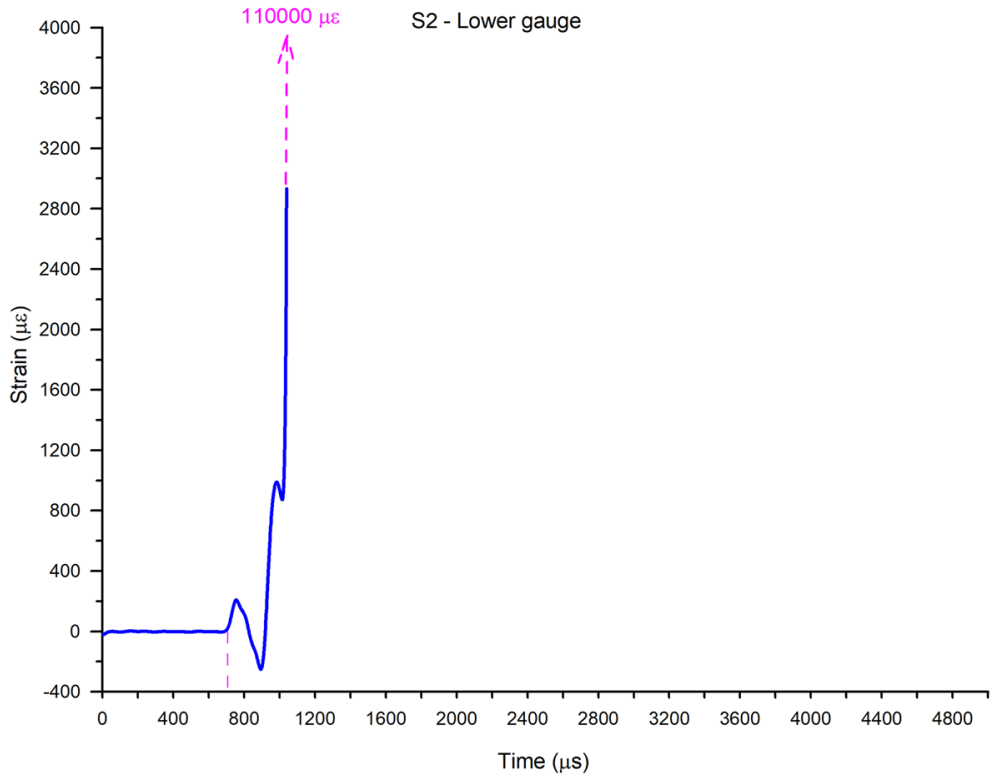

(c) 
Fig. 7 Photographs at $1140 \mu \mathrm{s}$ (Frame 20), $1710 \mu$ s (Frame 30), $2280 \mu$ s (Frame 40), and $2850 \mu$ s (Frame 50) after initiation of detonation of S4

(a) and tangential strain waves measured at middle strain gauge (b) and lower gauge (c) on the specimen
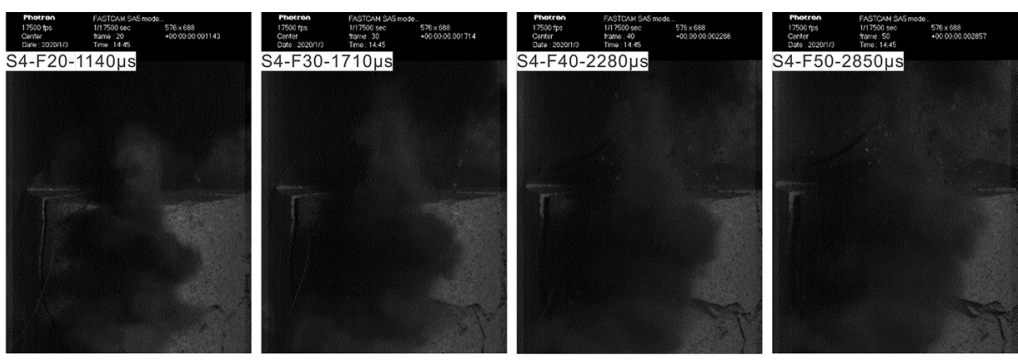

(a)

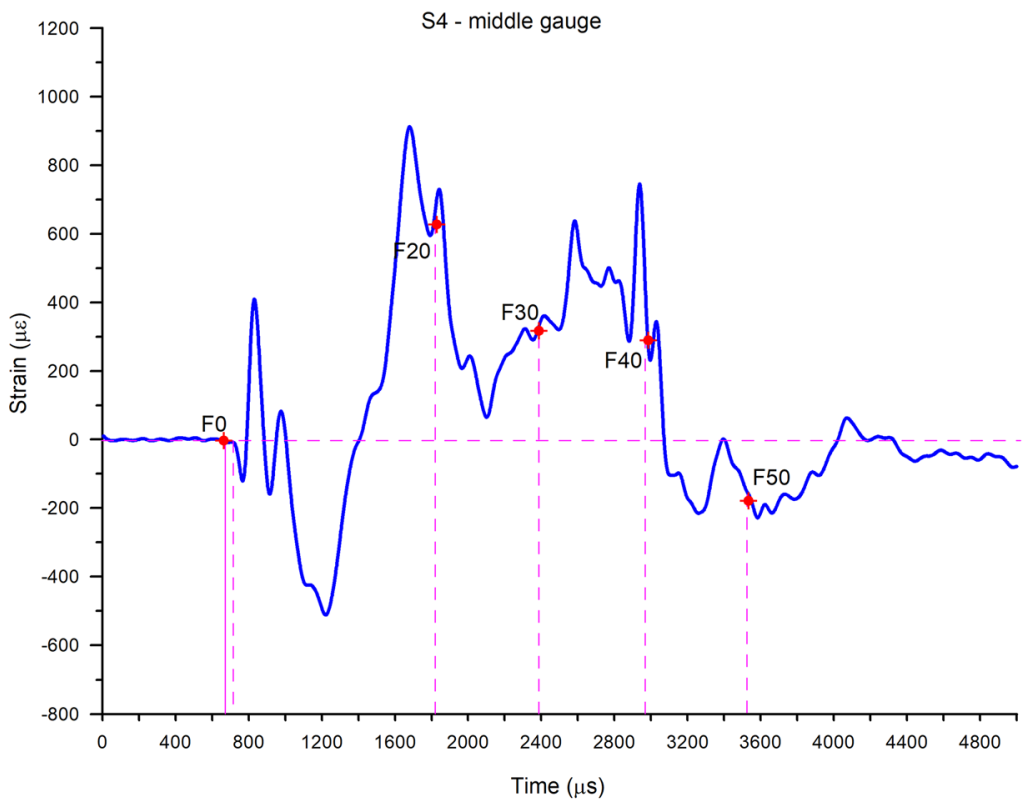

(b)

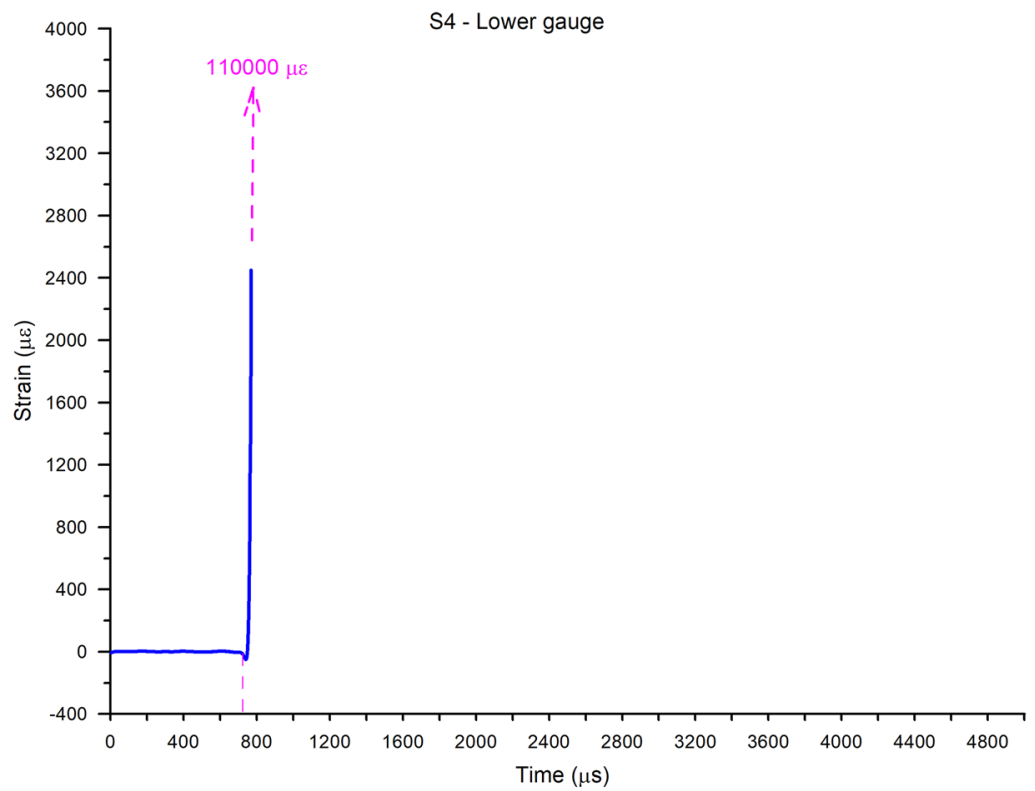

(c) 
Fig. 8 Photographs at $1140 \mu \mathrm{s}$ (Frame 20), $1710 \mu$ s (Frame 30), $2280 \mu$ s (Frame 40), and $2850 \mu$ s (Frame 50) after initiation of detonation of S5 (a) and tangential strain waves measured at middle strain gauge (a) and lower gauge (c) on the specimen
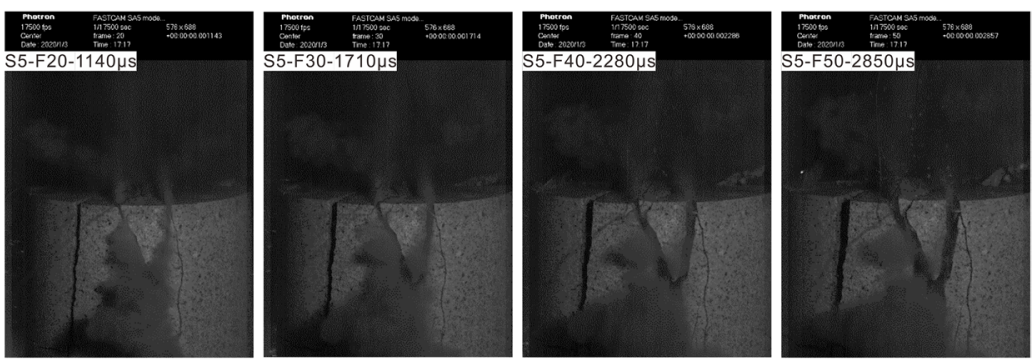

(a)

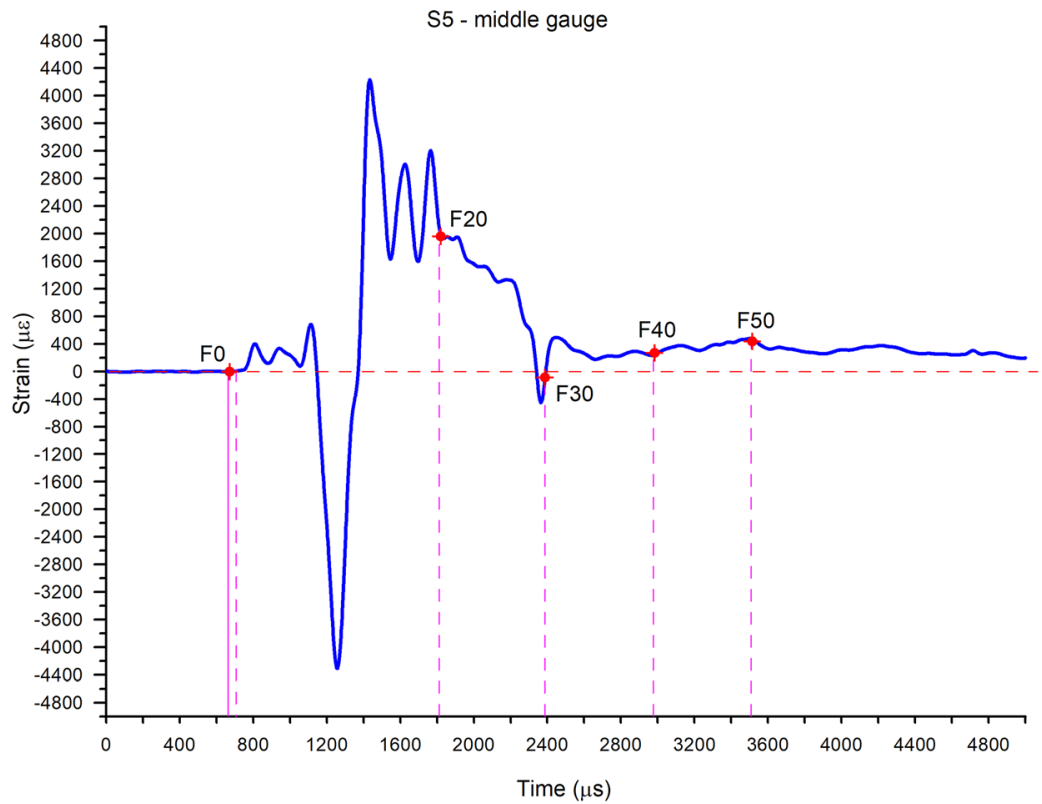

(b)

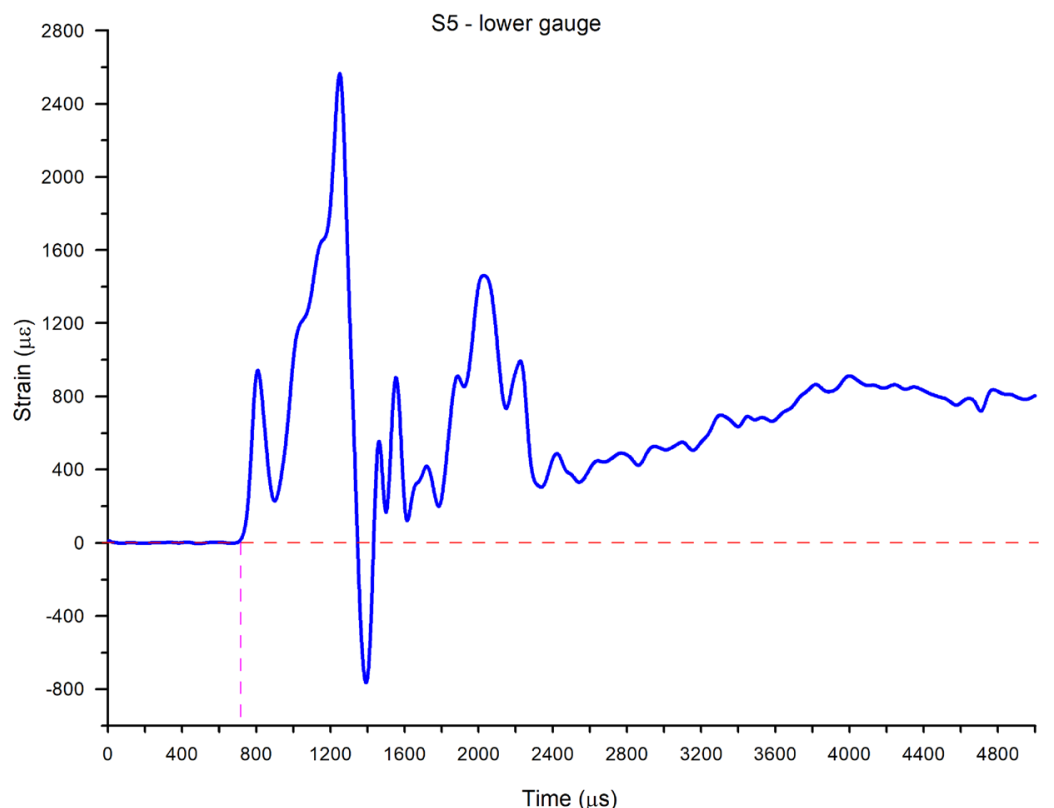

(c) 
Fig. 9 Photographs at $1140 \mu \mathrm{s}$ (Frame 20), $1710 \mu$ s (Frame 30), $2280 \mu$ s (Frame 40), and $2850 \mu$ s (Frame 50) after initiation of detonation of S9

(a) and tangential strain waves measured at middle strain gauge (b) and lower gauge (c) on the specimen
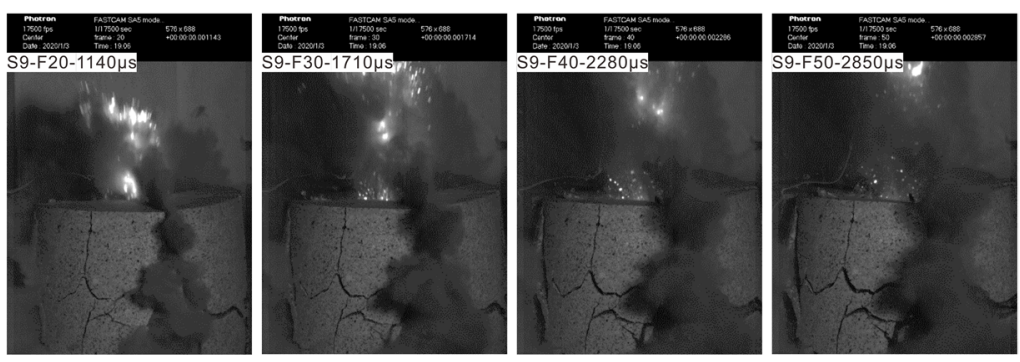

(a)

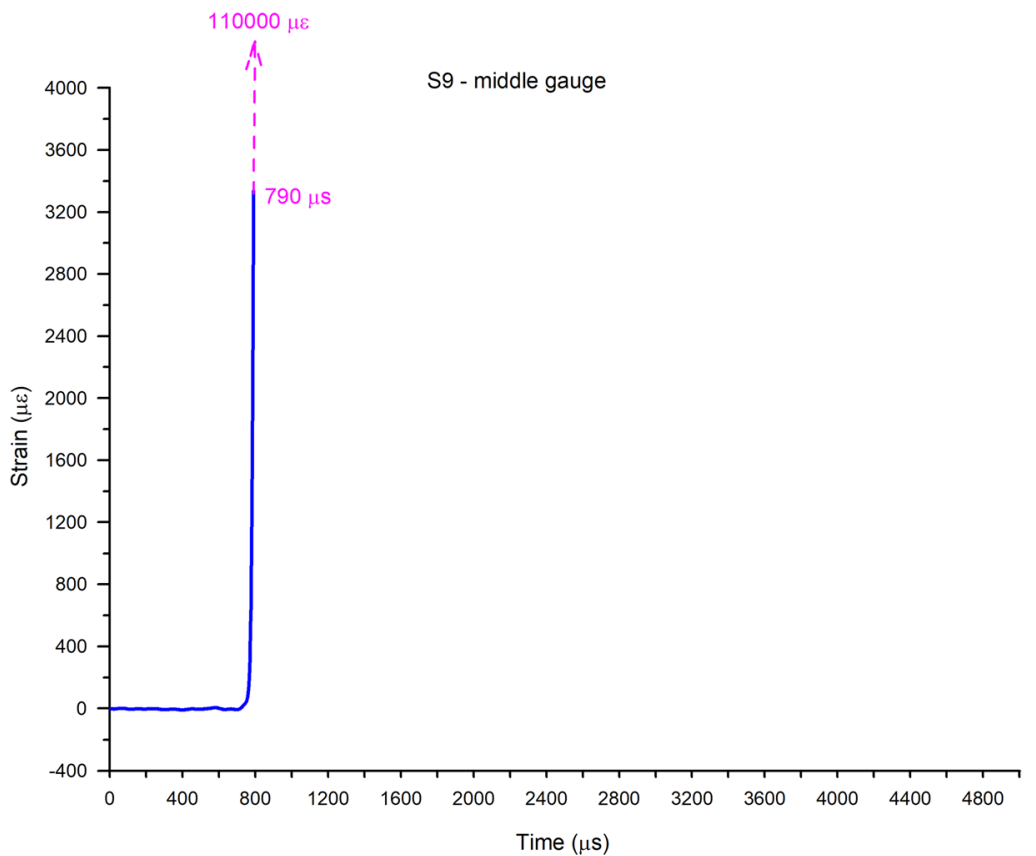

(b)

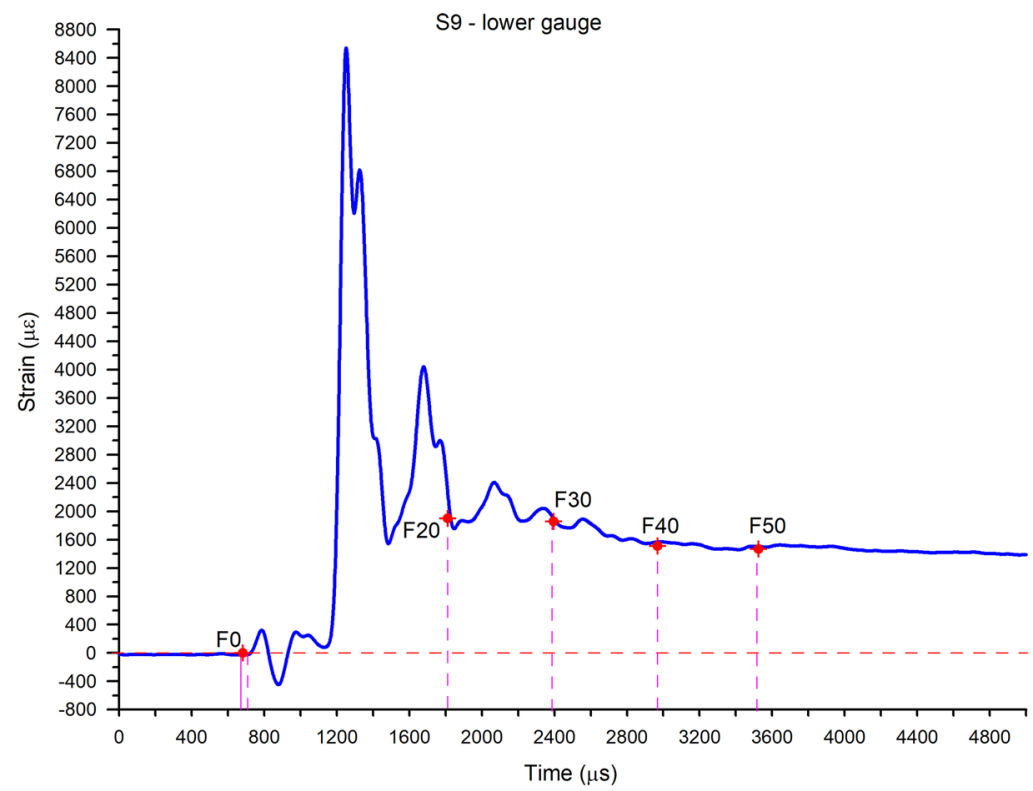

(c) 
front surface can be observed in frame 5. That is to say, the small crack was initiated much later than the earliest crack. Until frame $11(11 \times 57 \mu \mathrm{s})$, there had been no gas ejected from this earliest crack. Even until frame $50(50 \times 57 \mu \mathrm{s})$, see Fig. 8, there had been no gas ejection from this earliest crack. This fact indicates that this earliest crack might be initiated at the surface rather than at or near the blasthole (if nothing could completely stop the gas propagation from the blasthole in the earliest crack). A similar fact was reported by Chi et al. (2019a). Both facts support the theory of Fourney (2015) stating that as the P-wave from blasting hole arrives at the free surface of rock specimen, it is reflected back and the stress state becomes biaxial tensile. The biaxial tensile stress state initiates the flaws at or near the free surface in all directions, and the following $\mathrm{S}$-wave makes these flaw-caused cracks extend. Some of such cracks may start from the surface and propagate towards the interior of the specimen, resulting in the earliest cracks on the surface. As mentioned earlier, the travel time of the shock/ stress wave from the blasthole to the lateral free surface of specimen is about $27 \mu \mathrm{s}$, and the possible initiation time of the earliest crack on the free surface may be $114 \mu$ s after the initiation of detonation. If the chemical reaction time of the explosive and the rise time of the shock wave are assumed to be zero, the incubating time-the critical time for crack extension - of the earliest crack on the free surface will be equal to $114-27=87 \mu$ s. In rock fracture experiments under dynamic loading, it was found that this incubating time of gabbro and marble varied from 21 to $60 \mu \mathrm{s}$, and it mainly depended on the loading rates (Zhang et al. 1999, 2001). Obviously, the smallest difference is $87-60=17 \mu$ s. This difference is reasonable, since the chemical reaction and shock wave rise time are neglected and other unknown reasons may also exist. In brief, it is possible that some cracks observed on the free surface are initiated from the free surface rather than at or near the blasthole.

\subsection{Mechanism of Rock Fragmentation by Blasting}

As described by Zhang (2016), the explosive energy released during detonation in a blasthole is contained in the detonation wave (or called borehole pressure) that includes shock wave (in the front of detonation wave), the reaction zone, and the rarefaction wave that is in the form of detonation product gases. In other words, the energy in the gases has already been accounted for in the detonation wave. In this study, the length of the strain wave measured from middle gauges in each specimen was very long up to $2823 \mu$ s and the gas ejection from the surface cracks occurred in the whole duration, even longer than $2823 \mu \mathrm{s}$. At the same time, each rock specimen was still held at the original place but not completely disassembled apart. This implies that the loading time of gases with a pressure higher than the atmospheric pressure might be approximately equal to the length of the strain wave measured. As the cracks on the surface open to a certain size, the gases will mostly escape out of the rock and their pressure will decrease to the atmospheric pressure. Simultaneously, the strain waves will decrease to zero if the rock fragment on which strain gauge is attached is not loaded by any kind of load, e.g., no collision happens with another fragment or object. In brief, the gas energy (or most of gas energy) is possibly converted to stress waves acting to the rock in rock blasting.

\section{Conclusions}

Based on the experiments with strain measurement and highspeed photography at a framing speed of 17,500 frames per second, the following conclusions can be made:

The measured velocity of gas penetration into the radial cracks is in a range of $196-279 \mathrm{~m} / \mathrm{s}$.

The measured velocity of a radial crack extending from the blasthole to the specimen surface varies from 489 to $652 \mathrm{~m} / \mathrm{s}$.

The length of strain waves measured from the middle gauges is approximately $2820 \mu \mathrm{s}$, which is about 1000 times greater than the detonation time.

Gas ejection from some surface cracks lasts at least $2850 \mu$ s after detonation, and at the time $2850 \mu$ s, the specimens still stand in their original places, although they are completely broken and main cracks are open widely.

Acknowledgements This work is financed by K H Renlund Foundation in Finland. The third author is grateful to China Scholarship Council (CSC) for the support of his study.

Funding Open access funding provided by University of Oulu including Oulu University Hospital.

\section{Compliance with Ethical Standards}

Conflict of interest All author(s) declare that they have no conflict of interest.

Open Access This article is licensed under a Creative Commons Attribution 4.0 International License, which permits use, sharing, adaptation, distribution and reproduction in any medium or format, as long as you give appropriate credit to the original author(s) and the source, provide a link to the Creative Commons licence, and indicate if changes were made. The images or other third party material in this article are included in the article's Creative Commons licence, unless indicated otherwise in a credit line to the material. If material is not included in the article's Creative Commons licence and your intended use is not permitted by statutory regulation or exceeds the permitted use, you will need to obtain permission directly from the copyright holder. To view a copy of this licence, visit http://creativecommons.org/licenses/by/4.0/. 


\section{References}

Bergmann OR, Riggle JW, Wu FC (1973) Model rock blasting—effect of explosives properties and other variables on blasting results. Int J Rock Mech Min Sci Geomech Abstr 10:585-612. https://doi. org/10.1016/01489062(73)90007-7

Bhandari S (1979) On the role of stress waves and quasi-static gas pressure in rock fragmentation by blasting. Acta Astronaut 6:365-383

Chi LY, Zhang ZX, Aalberg A, Yang J, Li CC (2019) Fracture processes in granite blocks under blast loading. Rock Mech Rock Eng 52:853-868. https://doi.org/10.1007/s00603-018-1620-0

Chi LY, Zhang ZX, Yang J, Li CC, Aalberg A (2019) Measurement of shock pressure and shock-wave attenuation near a blast hole in rock. Int J Impact Eng 125:27-38. https://doi.org/10.1016/j.ijimp eng.2018.11.002

Chi LY, Zhang ZX, Aalberg A, Li CC (2019) Experimental investigation of blast-induced fractures in rock cylinders. Rock Mech Rock Eng. https://doi.org/10.1007/s00603-019-01749-0

Clark LD, Saluja SS (1964) Blasting mechanics. Trans Am Inst Min Engrs 229:78-90

Cooper PW (1996) Explosives engineering. Wiley-VCH, New York

Dally JW, Fourney WL, Holloway DC (1975) Influence of containment of the borehole pressures on explosive induced fracture. Int J Rock Mech Min Sci Geomech Abstr 12:5-12. https://doi. org/10.1016/0148-9062(75)91268-1

Duvall WI, Atchison TC (1957) Rock Breakage by Explosives. Bureau of Mines R.I, U.S

Fickett W, Davis WC (2000) Detonation: theory and experiment. Dover Publications, New York

Field JE, Ladegaard-Pedersen A (1971) The importance of the reflected stress wave in rock blasting. Int J Rock Mech Min Sci Geomech Abstr 8:213-326. https://doi.org/10.1016/0148-9062(71)90033-7

Fourney WL (2015) The role of stress waves and fracture mechanics in fragmentation. Blast Fragment 9:83-106

Fourney WL, Dally JW, Holloway DC (1974) Stress wave propagation from inclined line charges near a bench face. Int J Rock Mech Min Sci Geomech Abstr 11:393-401. https://doi.org/10.1016/01489062(74)91110-3

Fourney WL, Barker DB, Holloway DC (1981) Model studies of explosive well stimulation techniques. Int J Rock Mech Min Sci 18(2):113-127. https://doi.org/10.1016/0148-9062(81)90737-3

Fourney WL, Dick RD, Wang XJ, Wei Y (1993) Fragmentation mechanism in crater blasting. Int J Rock Mech Min Sci Geomech Abstr 30(4):413-429. https://doi.org/10.1016/0148-9062(93)91723-v

Fourney WL, Bihr S, Leiste U (2006) Borehole pressures in an air decked situation. Int J Rock Blast Fragm 10(1):47-60. https://doi. org/10.1080/13855140600858198

He C, Yang J, Yu Q (2018) Laboratory study on the dynamic response of rock under blast loading with active confining pressure. Int $\mathrm{J}$ Rock Mech Min Sci 102:101-108

Hino K (1954) Theory of blasting with concentrated charge. J Ind Explos Soc Japan 15(4):233-249

Jeong H, Jeon B, Choi S, Jeon S (2020) Fracturing behavior around a blasthole in a brittle material under blasting loading. Int J Impact Eng 140:103562. https://doi.org/10.1016/j.ijimpeng.2020.103562

Johansson D, Ouchterlony F (2013) Shock wave interaction in rock blasting: the use of short delays to improve fragmentation in model-scale. Rock Mech Rock Eng 46:1-18. https://doi. org/10.1007/s00603-012-0249-7

Johansson CH, Persson PA (1970) Detonics of high explosives. Academic Press, London, New York

Katsabanis P, Tawadrous A, Braun C, Kennedy C (2006) Timing effects on the fragmentation of small scale blocks of granodiorite. Int $\mathrm{J}$
Rock Blast Fragm 10:83-93. https://doi.org/10.1080/1385514060 0858339

Katsabanis P, Omidi O, Rielo O, Ross P (2014) Examination of timing requirements for optimization of fragmentation using small scale grout specimens. Blast Fragment 8:35-53

Kubota N (2001) Propellants and explosives, seconded. Wiley-VCH, Veinhein. https://doi.org/10.1002/3527600507

Kutter HK, Fairhurst C (1971) On the fracture process in blasting. Int J Rock Mech Min Sci 8:181-202. https://doi.org/10.1016/01489062(71)90018-0

Langefors U, Kihlström B (1963) The modern technique of rock blasting. Wiley, New York

Liu F, Guo Z, Lv H, Cheng Z (2018) Test and analysis of blast wave in mortar test block. Int J Rock Mech Min Sci 108:80-85. https:// doi.org/10.1016/j.ijrmms.2018.06.003

Mao X, Ma Y, Liu X (2020) Deformation characteristics and electrical resistivity response of soft coal under blast loading. Geotech Geol Eng 38:1205-1216. https://doi.org/10.1007/s10706-019-01082-x

Onederra IA, Furtney JK, Sellers E, Iverson S (2013) Modelling blast induced damage from a fully coupled explosive charge. Int J Rock Mech Min Sci 58:73-84. https://doi.org/10.1201/b13759-35

Ouchterlony F, Nyberg U, Olsson M, Bergqvist I, Granlund L, Grind H (2004) Where does the explosive energy in rock blasting rounds go? Sci Technol Energet Mater 65:54-63

Persson PA, Holmberg R, Lee J (1994) Rock blasting and explosives engineering. CRC Press, New York. https://doi.org/10.1201/97802 03740514

Sanchidrián JA, Pablo S, López LM (2007) Energy components in rock blasting. Int J Rock Mech Min Sci 44:130-147. https://doi. org/10.1016/j.ijrmms.2006.05.002

Sun C (2013) Damage zone prediction for rock blasting. In: $\mathrm{PhD}$ thesis, Department of Mining Engineering, The University of Utah

Tilert D, Svedbjörk G, Ouchterlony F, Nilsson B, Temun A, Mattsson L (2007) Measurement of explosively induced movement and spalling of granite model blocks. Int J Impact Eng 34:1936-1952. https://doi.org/10.1016/j.ijimpeng.2006.11.006

Yang R, Ding C, Yang L, Lei Z, Zheng C (2019) Study of decoupled charge blasting based on high-speed digital image correlation method. Tunn Undergr Space Technol 83:51-59. https://doi. org/10.1016/j.tust.2018.09.031

Zhang ZX (2016) Rock fracture and blasting: theory and applications. Butterworth-Heinemann/Elsevier, Oxford

Zhang ZX, Kou SQ, Yu J, Yu Y, Jiang LG, Lindqvist P-A (1999) Effects of loading rates on rock fracture. Int J Rock Mech Min Sci 36:597-611. https://doi.org/10.1016/S0148-9062(99)00031-5

Zhang ZX, Yu J, Kou SQ, Lindqvist P-A (2001) Effects of high temperatures on dynamic rock fracture. Int J Rock Mech Min Sci 38:211-225. https://doi.org/10.1016/S1365-1609(00)00071-X

Zhang ZX, Hou DF, Guo Z, He Z (2020) Laboratory experiment of stemming impact on rock fragmentation by a high explosive. Tunnel Undergr Space Technol 97:103257. https://doi.org/10.1016/j. tust.2019.103257

Zhang ZX, Hou DF, Guo Z, He Z, Zhang Q (2020) Experimental study of surface constraint effect on rock fragmentation by blasting. Int J Rock Mech Min Sci 128:104278. https://doi.org/10.1016/j. ijrmms.2020.104278

Publisher's Note Springer Nature remains neutral with regard to jurisdictional claims in published maps and institutional affiliations. 